\title{
Cátedra INEGI, un esfuerzo por fomentar la cultura estadística y geográfica
}

Con la inauguración de la Cátedra INEGI, la Universidad Veracruzana, a través de la Coordinación Universitaria de Observatorios Universitarios (CUO), del Instituto de Investigaciones en Estudios Superiores Económicos y Sociales (IIESES) y el Instituto Nacional de Estadística y Geografía (INEGI) emprendieron un compromiso conjunto para fomentar la cultura estadística y geográfica sustentada en la información que genera e integra el INEGI, brindando un panorama de alta calidad del quehacer institucional.

Desde el mes de agosto se han efectuado sesiones temáticas semanales integradas por una ponencia impartida por un experto del INEGI, una mesa de diálogo con la participación de investigadoras e investigadores de la Universidad Veracruzana y una sesión para preguntas, comentarios y reflexiones con el público participante.

La Cátedra INEGI ha sido transmitida a través del Sistema de Videoconferencias de la UV lo que ha facilitado la participación de las cinco regiones universitarias, además de darse a conocer no solo en el estado de Veracruz, sino en otras latitudes como la Ciudad de México, Puebla, Aguascalientes, Estado de México, Coahuila e incluso en Colombia, Argentina, Estados Unidos, Inglaterra y Alemania.

Les invitamos a acompañarnos en las últimas sesiones de la Cátedra INEGI que concluirá en el mes de noviembre acudiendo a algunas de las sedes de las regiones o siguiendo las transmisiones en vivo desde la página de Facebook de la Coordinación Universitaria de Observatorios, CUO UV.

Los próximos temas a tratar serán:

\begin{tabular}{|c|c|}
\hline 25 de octubre & $\begin{array}{c}\text { ¿Cómo hacer investigación utilizando distintas fuentes } \\
\text { de datos del INEGI? }\end{array}$ \\
\hline 08 de noviembre & Imágenes del Territorio \\
\hline 15 de noviembre & Censos Económicos \\
\hline
\end{tabular}

Para mayores informes pueden visitar el sitio: https://www.uv.mx/cuo/general/catedra-inegi/

\section{CÁTEDRAINEG}

Del 9 de agosto al 15 de noviembre de 2018

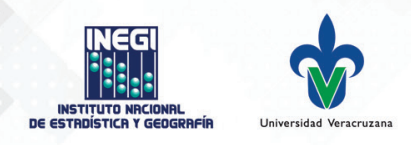

